\title{
Marfan syndrome with unileaflet mitral valve, moderate mitral regurgitation and atrial septal defect. An uncommon association
}

Nilda Espinola-Zavaleta ${ }^{1,2 *}$, Rodrigo Escalante-Armenta ${ }^{1,3}$, Dana Leyla Rei-Cassab ${ }^{4}$, Luis Javier Castellanos-Vizcaíno ${ }^{1,4}$ and Erick $^{4}$ Alexanderson-Rosas ${ }^{1,5}$

${ }^{1}$ Department of Nuclear Cardiology, National Institute of Cardiology Ignacio Chavez, Mexico City, Mexico

${ }^{2}$ Department of Echocardiography, ABC Medical Center I.A.P., Mexico City, Mexico

${ }^{3}$ Mexican Faculty of Medicine, LaSalle University, Mexico City, Mexico

${ }^{4}$ Health Sciences Faculty, Anahuac University, State of Mexico, Mexico

${ }^{5}$ Department of Physiology, Faculty of Medicine, National Autonomous University of Mexico, Mexico City, Mexico

\begin{abstract}
This is a case of a patient with Marfan Syndrome, who has as outstanding characteristics of a unicuspid mitral valve with moderate mitral regurgitation and atrial septal defect, both reported in an echocardiographic study. The association between both congenital cardiovascular alterations is very rare, and even more as unique findings in a patient with Marfan Syndrome.
\end{abstract}

\section{Introduction}

One of the most common connective tissues inherited disease is Marfan Syndrome (MFS), an autosomal dominant condition with a reported incidence of 1 in every 3000 to 5000 individuals [1]. MFS suffers mutations in gene FBN1 located in chromosome 15q21.1 encoding for the protein fibrillin-1, which is the main component of extracellular matrix of connective tissue. MFS is also characterized by having a variable expressiveness; therefore, the clinical picture of the disease can vary among individuals [2].

Cardinal features of MFS involving the cardiovascular system are aortic root disease, leading to aneurysmal dilatation, aortic regurgitation, and dissection, are the main causes of morbidity and mortality in the MFS [1]. Cardiovascular manifestations in Marfan syndrome also include valvular disease including mitral valve, aortic valve or both [3]. Mitral valve prolapse is the most prevalent valvular abnormality within patients with MFS [4].

Atrial septal defects are the most common congenital heart lesions in adults after bicuspid aortic valves [5]. Atrial septal defects account for approximately 10 to $15 \%$ of congenital heart disease, with a reports birth prevalence of 1 to 2 per 1000 live births [6].

The prevalence of atrial septal defect in Marfan syndrome is approximately of $4 \%$, being the ostium secundum the most frequent type [7].

The echocardiogram is the gold standard for congenital cardiopathies diagnoses and follow-up, especially the three-dimensional modality, which allows the precise characterization of interatrial septal defects and mitral valve anatomy [8].

\section{Case presentation}

A 26-year-old male with a family history of Marfan Syndrome (mother and grandmother) with the diagnosis of Marfan syndrome, comes with us asymptomatic for a clinical and echocardiographic review.

On cardiac examination a rhythmic heart sounds, systolic murmur in pulmonary focus, wide and fixed split of the second noise were evidenced.

The transthoracic and transesophaegal echocardiogram reported dilatation of the right cavities, ostium secundum atrial septal defect with an area of $4.12 \mathrm{~cm} 2$, left to right shunt (Figure 1), QP / QS 1.8: 1.0, mild pulmonary hypertension with pulmonary artery systolic pressure (PASP) of $40 \mathrm{mmHg}$, unicuspid mitral valve with prolapse and moderate mitral regurgitation, normal biventricular systolic function and slight dilation of the aortic root and sinuses of Valsava $(35 \mathrm{~mm})$, rest of the aortic segments with normal diameters.

He underwent for percutaneous closure of the atrial septal defect with an Amplatzer device, which was successful, (Video 1 and Figure 2).

${ }^{\star}$ Correspondence to: Nilda Espinola-Zavaleta; $\mathrm{MD}, \mathrm{PhD}$, Juan Badiano $\mathrm{N}^{\circ}$ 1, Colonia Seccion XVI, Tlalpan, P.C. 14080, Mexico City, Mexico, E-mail: niesza2001@hotmail.com

Key words: Marfan syndrome, atrial septal defect, unicuspid mitral valve, mitral regurgitation, echocardiography

Received: January 14, 2019; Accepted: January 22, 2020; Published: January 27, 2020 


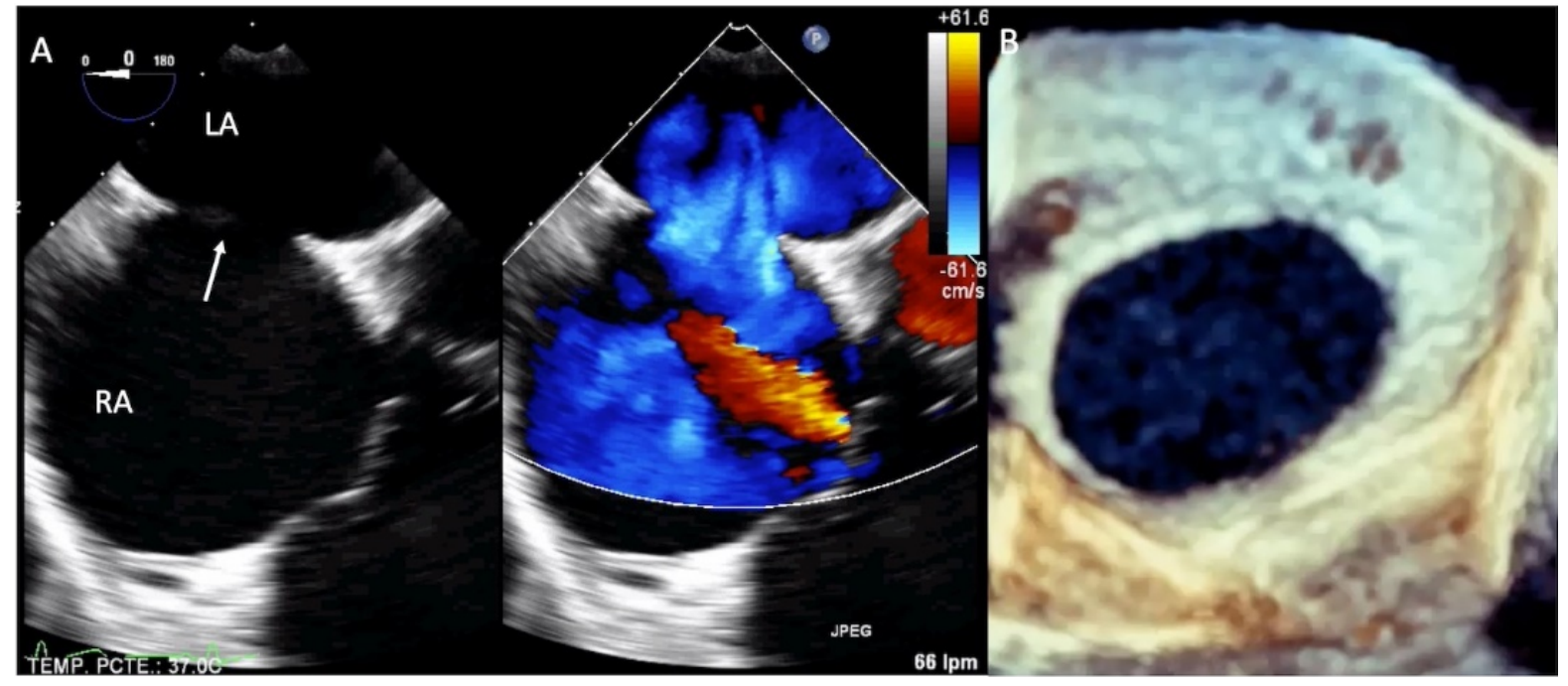

Figure 1. Bidimensional with color Doppler (A) and three-dimensional transesophageal echocardiography (B) showing the ostium secundum atrial septal defect, with adequate borders for percutaneous closure and mild tricuspid regurgitation

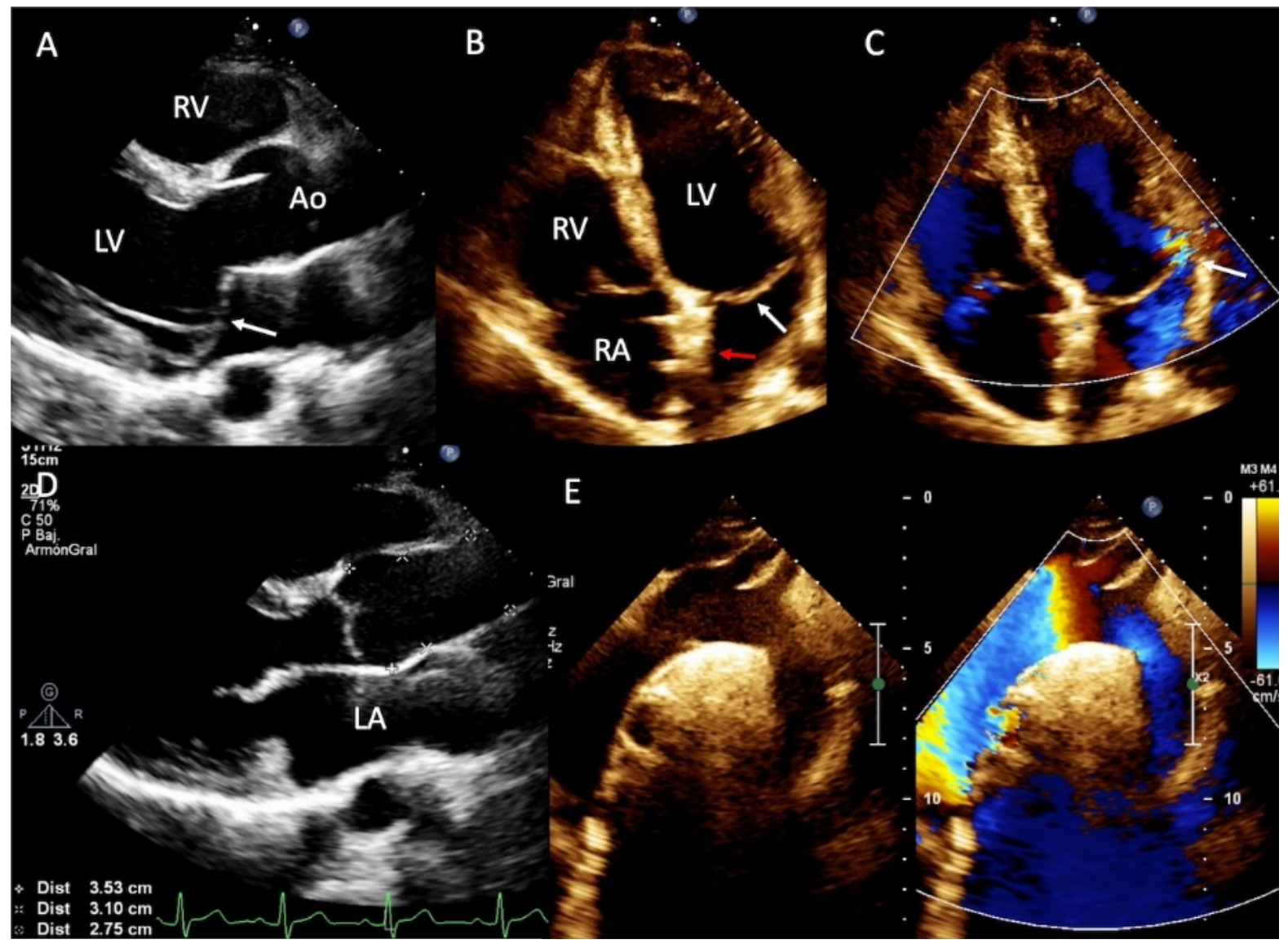

Figure 2. Transthoracic bidimensional and color Doppler echocardiography. A- Long parasternal axis view showing uniscuspid mitral valve with prolapse (white arrow). B-Apical four chamber view with successful closure of ostium secundum atrial septal defect by Amplatzer device (red arrow) and unicuspid mitral valve with prolapse (white arrow). C-Four chamber view showing unicuspid mitral valve with moderate mitral regurgitation (white arrow). A slight dilation of the aortic root and sinuses of Valsava was detected (D), the diameters of ascending aorta, aortic arch and descending aorta (E) are normal

The follow-up echocardiogram showed right cavities with normal diameters, interatrial septum with well-implanted Amplatzer device, without evidence of residual shunt, PASP $25 \mathrm{mmHg}$, unicuspid mitral valve, moderate mitral regurgitation, normal biventricular systolic function, and slight dilation of the aortic root and sinuses Valsava (35 $\mathrm{mm}$ ), the rest of the aortic segments continues in normal diameters.

Currently the patient is in NYHA functional class 1, with an annual echocardiographic monitoring. 


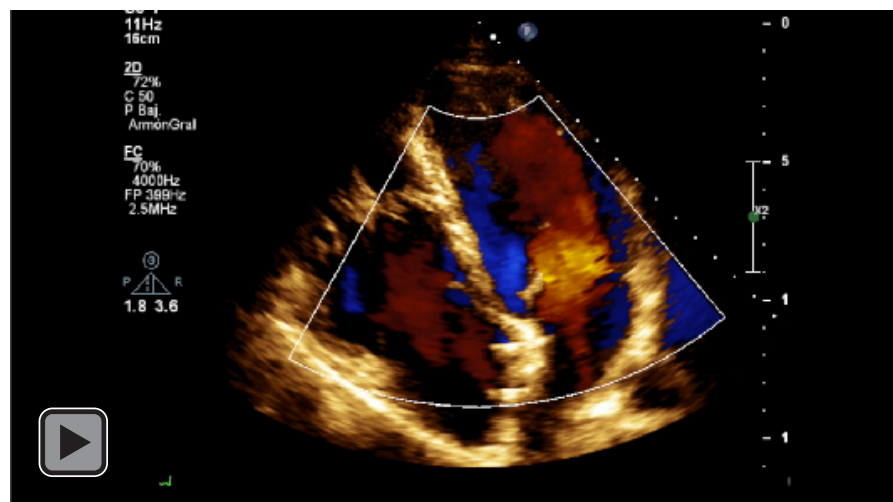

Video 1. Four chamber view showing unicuspid mitral valve with moderate mitral regurgitation, mild tricuspid regurgitation and successful closure of ostium secundum atrial septal defect by Amplatzer device

\section{Discussion}

We present a case of a young male with diagnosis of MFS and cardiovascular disease of ostium secundum atrial septal defect associated with unileaflet mitral valve with prolapse and moderate mitral regurgitation. MFS is often related to cardiovascular disease, but neither the interatrial communication nor the mitral prolapse are among the most frequent cardiovascular diseases related to adults with MFS. The most prevalent cardiac defect among patients with MFS is the dilatation of the aorta, which is found in approximately 50 percent of young children with MFS and progresses with time [1]. In the echocardiographic report of our patient there is a slight dilatation of the aortic root and sinus of Valsalva $(35 \mathrm{~mm})$, but it is the least significant finding of his report.

Unileaflet mitral valve with prolapse and moderate mitral regurgitation is a very rare finding. The absence of posterior mitral valve leaflet is usually fatal in utero, if presented in childhood it tends to be associated with symptomatic mitral regurgitation that requires surgical repair [9]. On the other hand, our patient is asymptomatic, with NYHA functional class I, despite moderate mitral regurgitation, something little expected for the pathology.

Atrial septal defects account for approximately 10 to 15 percent of congenital heart disease, with a prevalence of 1 to 2 per 1000 live births [6]. There have been described cases of ostium primum atrial septal defect associated with unileaflet mitral valve due to its embryological common grounds, but the association between unileaflet mitral valve and ostium secundum is extremely rare [10]. There is very few reports of ostium secundum associated with unileaflet mitral valve in literature, and even less as a congenital cardiac defect in an MFS patient.

Transesophageal two-dimensional and three-dimensional echocardiogram is considered the best method for assessment of the mitral valve and subvalvular apparatus [11].

The closure of ostium secundum interatrial septal defect with an Amplatzer device seems to be the standard treatment, on the other hand, the mitral valve replacement will be performed when the degree of regurgitation is severe [12].

\section{Conclusions}

Marfan syndrome associated with ostium secundum atrial septal defect and unicuspid mitral valve with prolapse is extremely rare.

The echocardiogram is the best non-invasive method for diagnosis and follow-up of congenital cardiopathies.

\section{Highlights}

Marfan syndrome is often related to cardiovascular disease.

The unicuspid mitral valve is very rarely associated with ostium secundum atrial septal defects.

The echocardiogram is the method of choose for diagnosis and follow-up of patients with Marfan syndrome.

\section{Financial support}

No financial support.

\section{Conflicts of interest}

No conflict of interest between the authors.

\section{Ethical standards}

The authors assert that all procedures contributing to this work comply with the ethical standards of the relevant national guidelines on human experimentation and with the Helsinki Declaration of 1975, as revised in 2008, and has been approved by the institutional committees.

\section{References}

1. Judge DP, Dietz HC (2005) Marfan's syndrome. Lancet 366: 1965-1976. [Crossref]

2. Barriales-Villa R, García-Giustiniani D, Monserrat L (2011) Genética del síndrome de Marfan. Cardiocore 46: 101-104.

3. Milewicz DM, Dietz HC, Miller DC (2005) Treatment of aortic disease in patients with Marfan syndrome. Circulation 111: e150-e157.

4. Van Karnebeek CD, Naeff MS, Bulder BJ, Hennekam RC, Offringa M (2001) Natural history of cardiovascular manifestations in Marfan syndrome. Arch Dis Childhood 84: 129-137.

5. Warnes CA, Williams RG, Bashore TM, Child JS, Connolly HM, et al. (2008) ACC AHA 2008 Guidelines for the management of adults with congenital heart disease. Circulation 118: 2395-2451.

6. Praagh SV, Porras D, Oppido G, Geva T, Praagh RV (2003) Cleft mitral valve withou ostium primum defect: anatomic data and surgical considerations based on 41 cases. Ann Thorac Surg 75: 1752-1762.

7. Stuart AG, Williams A (2007) Marfan's syndrome and the heart. Arch Dis Child 92: 351-356.

8. Parato VM, Masia SL (2018) Hypoplasia or absence of posterior leaflet: A rare congenital anomaly of the mitral valve in adulthood - Case Series. $J$ Cardiovasc Echogr 28: 45-47.

9. Espinola-Zavaleta N, Escalante-Armenta R, Castellanos-Vizcaino LJ, AlexandersonRosas E (2019) Rare association between atrial septal defect and unicuspid mitral valve: Case report. Clin Med Invest 4: 2-2.

10. Espinola-Zavaleta N, Vargas-Barrón J, Keirns C, Rivera G, Romero-Cárdenas A, et al (2002) Three-dimensional echocardiography in congenital malformations of the mitral valve. J Am Soc Echocardiogr 15: 468-472.

11. Farmer D, Sitkin N, Lofberg K, Donkor P, Ozgediz D (2015) Surgical interventions for congenital anomalies. In: Debas HT, Donkor P, Gawande A, Jamison DT, Kruk ME, et al. (Eds) Essential Surgery: Disease Control Priorities 1: 129-149.

Copyright: (C2020 Espinola-Zavaleta N. This is an open-access article distributed under the terms of the Creative Commons Attribution License, which permits unrestricted use, distribution, and reproduction in any medium, provided the original author and source are credited. 